\title{
THE ROLE OF PHYSICAL ACTIVITY IN PSYCHOLOGICAL RESILIENCE
}

\author{
Abdullah Bora Ozkara, Arslan Kalkavan, Serdar Alemdag, Ceyhun Alemdag \\ Karadeniz Technical University, Trabzon, Turkey
}

\begin{abstract}
Background. Existing research indicates that both teachers and prospective teachers who are physically active in comparison with inactive generally easier cope with physical and psychosocial problems. This topic, particularly psychosocial development of individuals and their participation in sports, has attracted the attention of researchers in recent years. There are a lot of studies on this issue, but less is known about the relationship between physical activity participation and psychological resilience. Therefore, the purpose of this study was to determine the association between experience of physical activity and psychological resilience of prospective teachers according to some variables.

Methods. A sample of 331 last year student teachers (134 females and 197 males) who study at the Faculty of Education at Karadeniz Technical University in Northeast Turkey was evaluated. We used Childhood and Adolescence Physical Activity Levels Questionnaire to determine the physical activity experience. Besides, we applied the Brief Resilience scale to analyse the psychological resilience. The data was analysed by using the Pearson's Correlation Coefficient, Simple Linear Regression and Independent Sample $t$-Test.

Results. The research findings show that there was positive and significant relationship between psychological resilience and physical activity experience of prospective teachers. Regression analysis revealed that participation of physical activity was found to be significant predictors of resilience. In addition, both physical activity levels and resilience of prospective teachers with respect to gender, department and licensed sports participation status were found significant.

Conclusions. Physical activity has numerous beneficial psychological effects. Furthermore, current research results suggest that experiences of physical activity play a role in psychological resilience of prospective teachers. It was also concluded that prospective teachers should be encouraged to participate in physical activity. The development of this aspect of the policy can contribute to psychological resilience of prospective teachers.
\end{abstract}

Keywords: sport, psychological resilience, teacher education.

\section{INTRODUCTION}

$\mathrm{P}$ articipation in physical education and sports activities at school during childhood and youth is an important opportunity for the acquisition of healthy lifestyle and physical activity habits and for the transfer of such habits to the later stages of our lives. Physical activity is known to have a role in the maintenance of a healthy weight and the enhancement of fitness, endurance, strength and flexibility as well as reducing the risk of chronic diseases that are considered as today's diseases (Central for Disease Control and Prevention, 2008;
The Ministry of Health Public Health Agency of Turkey, 2014). Regular physical activity not only provides protection and prevention against such diseases but also reduces the risk of obesity and contributes to the cognitive and psychological robustness (Guiney, Lucas, Cotter, \& Machado, 2015; Walker, Sechrist, \& Pender, 1987). Bandura (1993) notes that being physically active has a positive effect on overcoming psychological and social problems and contributes particularly to the self-efficacy of teachers constituting the sample group of this research. 
Research addressing problems experienced in teacher training has in recent years grown in importance across the world (C. Alemdağ \& Öncü, 2015; S. Alemdağ \& Öncü, 2015; Caz \& Tunçkol, 2013; Hamilton, 2016; Hein, Koka, \& Hagger, 2015; Maciulevičienė \& Gedviliené, 2014; Reeves \& Lowenhaupt, 2016; Yazıc1\&Altun, 2013). Especially the first years of service have significant effects on the professional development of teachers (Paquette \& Rieg, 2016; Sharplin, O’Neill, \& Chapman, 2011). In developed and developing countries, teachers often complain of such problems as job withdrawal, burnout and lack of self-confidence and self-esteem within the first five years of their career; and rates of teacher turnover are also quite high in these years (Allensworth, Ponisciac, \& Mazzeo, 2009; Graham, Parmer, Chambers, \& Tourkin, 2011). Efforts made to overcome problems encountered in this period increase the importance of the concept of psychological resilience (Cornu, 2009). Psychological resilience is defined as the capacity to cope with and tolerate challenging or troublesome circumstances and to adapt or recover despite adverse conditions (Masten, Best, \& Garmezy, 1990; Ramirez, 2007; Reich, Zautra, \& Hall, 2010;). It is a well-known fact that undesirable situations encountered in teaching profession where psychological pressure is felt more than in other occupations (Çelebi \& Oğuzöncül, 2013) should be handled because teachers are expected to not only fulfil their responsibilities for teaching and training activities but also to support students' academic and social development. Psychological resilience, which is also defined as the ability to bounce back from problems faced in the school environment with a dynamic structure and to successfully adapt to a new situation (Doğan, 2015), is believed to be a key ability for teachers and preservice teachers. The positive effects of participation in sports and physical activity on coping with challenging or threatening conditions have been revealed by a considerable number of studies (Penedo \& Dahn, 2005; Salmon, 2001; Southwick, Vythilingam, \& Charney, 2005; Wankel \& Berger, 1990; Warburton, Nicol, \& Bredin, 2006). There is a lot of research on this issue, but less is known about the relationship between physical activity participation and psychological resilience. The current study will also be contribute to the literature in Turkey to eliminate the lack of research on relationship between physical activity and psychological resilience of teachers.
Therefore, the aim of this study was to determine the association between experience of physical activity and psychological resilience of prospective teachers according to some variables and establish whether physical activity has a predicting effect on psychological resilience of preservice teachers.

\section{METHODS}

This study is based on descriptive survey design and examines preservice physical education teachers' participation in physical activity and psychological resilience. A sample of 331 senior preservice teachers (134 females and 197 males) studying at the Faculty of Education at Karadeniz Technical University in Northeast Turkey was evaluated. All of the preservice teachers of physical education, English, mathematics and Turkish language teaching completed a teaching internship for at least one semester at primary schools. After the required permits were obtained, data was collected by means of related scales at the end of the internship in February 2015.

We used Childhood and Adolescence Physical Activity Levels Questionnaire to determine the physical activity experience. Childhood and Adolescence Physical Activity Levels Questionnaire developed by Masiie (2002) is a scale used to measure participation levels in physical activities at four educational stages (primary school, secondary school, high school and university) (Saygin \& Ayhan, 2015). Total scores were calculated based on the physical activity participation levels of preservice teachers at primary school, secondary school, high school and university For each developmental level, participants were asked about their level of participation in physical activity in four different venues (physical education classes, organized_youth sports, sport specific lessons, and informal physical activities). For these eight items, a five-point Likert-type scale measured frequency, where $1=$ "never or almost never" (0-20\%), $2=$ "rarely" (21-40\%), $3=$ "sometimes" (41-60\%), 4 = "often" (61-80\%), $5=$ "almost always or always" (81-100\%), and na = "not applicable" (Massie, 2002). This measurement instrument was preferred as it addresses both individuals' past physical activity experiences and current participation in physical activity. Participation in physical activity was considered as a process. Childhood and adolescence physical activity levels questionnaire allows us to determine individuals' 
past and current physical activity levels. Scores obtain from the questionnaire consists of the sum of current level, adolescence level and childhood level of physical activity scores. This scale not only provides us the current sitiation but also overall process of individuals physical activity levels.

Besides, we applied the Brief Resilience scale to analyse psychological resilience. The short form of this scale developed by Smith at al. (2008) focuses on individuals' characteristics of bouncing back, recovering from stress, functioning again and readapting, which is different from the scales described, and adapted in Turkish by Doğan (2015). The scale consist of six items. While 1,3 , and 5 are positevly; 2, 4, 6 are negatively worded. A fivepoint Likert-type scale measured the following: $1=$ strongly disagree, $2=$ disagree, $3=$ neutral, $4=$ agree, 5 = strongly agree.".

\section{RESULTS}

The research findings show that there was positive and significant relationship between psychological resilience and physical activity experience of prospective teachers. Regression analysis revealed that participation in physical activity was found to be significant predictors of resilience.

The correlation coefficient, $r$, was found to be $r=.598$. Physical activity level was adequate and significantly positively correlated with psychological resilience. $(r=.59, p<.001)$. The implication of this $r$ value leads to the deduction that $59.8 \%$ of the dependent variable is explained by the independent variable. In other words, $59.8 \%$ of the psychological resilience that was displayed by the subjects, in this case preservice teachers, was explained by the participation in the physical activities. This research process is consequently $99 \%$ certain that physical activity promotes psychological resilience. The relationship between physical activity and psychological resilience is shown in Table 1 and Figure.

Table 1 . The correlation results of physical activity and psychological resilience

\begin{tabular}{|l|c|c|c|}
\hline \multirow{2}{*}{} & \multicolumn{3}{|c|}{ Resilience } \\
\cline { 2 - 4 } & $\mathbf{n}$ & $\mathbf{r}$ & $\mathbf{p}$ \\
\hline Physical Activity & 331 & $.59^{* *}$ & .00 \\
\hline
\end{tabular}

Note. $* * p<.001$.

Simple lineer regression was used in order to estimate predictive relations between participation of physical activity and psychological resilience. A significant regression equation was found $(F(1,329)=183.095, p<.000)$ with an $R^{2}$ of .358 . There is a direct relationship between the two variables under analysis and it is also a positive
Figure. The relationship between physical activity and psychological resilience

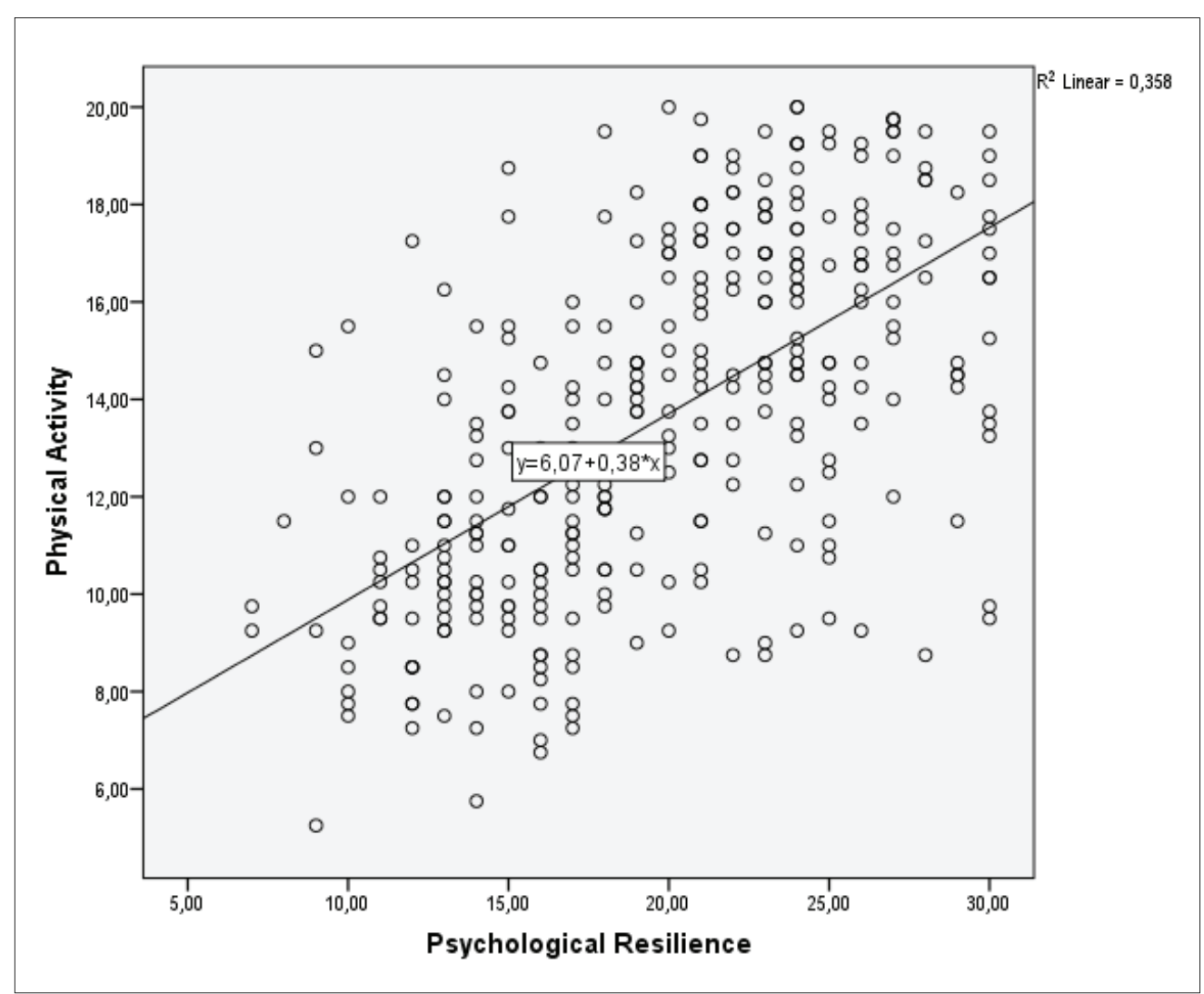




\begin{tabular}{|l|c|c|c|c|c|}
\hline & B & St. Error $_{\text {в }}$ & $\boldsymbol{\beta}$ & $\boldsymbol{t}$ & $\boldsymbol{p}$ \\
\hline Constant & 7,000 & .972 & - & 7.201 & .000 \\
\hline $\begin{array}{l}\text { Physical } \\
\text { Activity }\end{array}$ & .936 & .069 & .598 & 13.531 & .016 \\
\hline$R=.598$ & $R^{2}=.358$ & & & \\
\hline$F_{(1,329)}=183.095$ & $p=.000$ & & & \\
\hline
\end{tabular}

relationship between physical activity and psychological resilience. In other words, the more the individual participates in activities of physical exercise, the greater the psychological resilience that he or she displays. The vice versa is also true; the less the physical activity, the less the level of psychological resilience. Regression analysis results on physical activity and psychological resilience are given in Table 2.

\section{DISCUSSION}

Psychological resilience is the differences between people in how they respond to and cope with difficult or stressful experience. Teaching profession is one of the careers full of adversities. This is due to the frequent interaction with children who typically do not care about anything. Consequently, this leads to stress and a lot of anger among teachers. This report confirms that there is one of the most natural ways of dealing with adversities, that being through engagement in physical activity. Scientifically, as suggested by Spalding et al. (2004), the fact proved by the above research may be due to the fact that physical activity leads to improvements in general cardiac performance - the cardiovascular system becomes more efficient and does not need to do as much work to mobilize resources in reaction to a stressor. As evident from the above results, there is a great correlation between physical activity and psychological resilience. When the body gets to be active, mostly in prospective teachers, they tend to be more resilient to adversities in their work. They can stand disappointments, stress and demoralizing situations. Teachers, evidently those who take basic courses such as entertainment and sports, tend to be more resilient due to the fact that they end up practicing as a way of encouraging students in sports activities. This is due to the fact that a sport is a typical physical activity. Teachers who were non-exercisers exhibited a greater decline in positive effect during the test as compared to exercisers. These findings provide the best support for claims that regular exercise protects against the negative emotional consequences of stress.

The implication of this particular study is that it can be used for the purposes of policy implementation. Resilience is one positive trait that is much needed by most individuals particularly with the understanding that it is indeed very effective in terms of stress adaptability. With the direct and positive relationship between resilience and physical activity that has been established in the preceding section of this analysis, physical activity should be encouraged amongst teachers, through various policies in order to promote resilience. Further, this particular research process also highlighted the fact that $59.8 \%$, approximately equal to about two thirds, of the psychological resilience that was showcased by the subjects was explained by their participation in physical activities. However, $40.2 \%$ was explained by other factors not within the model. In order to develop comprehensive empirical and theoretical research, future studies should consider substantiating these other factors, other than physical activity, that promote psychological resilience.

\section{CONCLUSION}

Physical activity has numerous beneficial psychological effects. Furthermore, with current research results suggest that experiences of physical activity play a role in psychological resilience of prospective teachers. It was also concluded that prospective teachers should be encouraged to participate in physical activity. The development of this aspect of the policy can contribute to psychological resilience of prospective teachers. Therefore, prospective teachers should be encouraged to engage in physical activities to improve their psychological resilience. In current study the physical activity levels used self-reported questionnaire and all participants came from a single school site. For 
future research, a wider diversity of prospective teachers from multiple schools may be included to expand the generalizability of these findings. Also instead of self-reported questionnaires, pedometers or accelerometers can be used to measure physical activity levels. In summary, while acknowledging the limited transferabillty of current study to generalizations for teachers, this study emphasizes that physical activity has a significant impact on psychological resilience of prospective teachers.

\section{REFERENCES}

Alemdağ, S., \& Öncü, E. (2015). Öğretmen Adaylarının Fiziksel Aktiviteye Katılım ve Sosyal Görünüş Kaygılarının İncelenmesi. International Journal of Science Culture and Sport, 3(Özel Say1), 287-300. doi:10.14486/IJSCS291

Alemdağ, C., \& Öncü, E. (2015). Pre-service physical education teachers according to Kolb's Model of Learning Style. Alan Eğitimi Araştırmaları Dergisi, 1(1), $1-12$.

Allensworth, E., Ponisciac, S., \& Mazzeo, C. (2009). The schools teachers leave. Chicago: Teacher Mobility in Chicago Public Schools. Retrieved 04 20, 2016, from https://consortium.uchicago.edu/sites/default/files/ publications/CCSR_Teacher_Mobility.pdf

Bandura, A. (1993). Perceived self-efficacy in cognitive development and functioning. Educational Physhologist, 28(2), 117-148.

Caz, Ç., \& Tunçkol, H. M. (2013). Investigation of physical education and sport teacher candidates' time management skills. CBU Journal of Physical Education and Sport Sciences, 8(2), 23-29.

Çelebi, E., \& Oğuzöncül, A. F. (2013). Determination of some health behaviors of special education teachers. Firat University Journal of Health Sciences, 27(2), 8792.

Central for Disease Control and Prevention. (2008). Physical activity guidelines for Americans. Washington: U.S. Department of Health and Human Services.

Cornu, R. L. (2009). Building resilience in pre-service teachers. Teaching and Teacher Education, 25, 717-723.

Doğan, T. (2015). Adaptation of the Brief Resilience Scale into Turkish: A validity and reliability study. The Journal of Happiness \& Well-Being, 3(1), 93-102.

Graham, S., Parmer, R., Chambers, L., \& Tourkin, S. (2011). Teacher follow-up survey. Institute of Education Sciences, U.S. Department of Education. Washington: The National Center for Education Statistics. Retrieved 04 26, 2016, from http://nces.ed.gov/pubs2011/2011304. pdf

Guiney, H., Lucas, S., Cotter, J., \& Machado, L. (2015). Evidence cerebral blood-flow regulation mediates exercise-cognition links in healthy young adults. Neuropsychology, 29(1), 1-9. doi:10.1037/neu0000124

Hamilton, E. R. (2016). Picture this: Multimodal representations of prospective teachers' metaphors about teachers and teaching. Teaching and Teacher Education, 55, 33-44.
Hein, V., Koka, A., \& Hagger, M. S. (2015). Relationships between perceived teachers' controlling behaviour, psychological need thwarting, anger and bullying behaviour in high-school students. Journal of Adolescence, 42, 103-114.

Karasar, N. (2008). Bilimsel Araştırma Yöntemi. Ankara: Nobel.

Maciulevičienè, E., \& Gedvilienė, J. (2014). Subjective perception of the realities of modern physical education calsses among physical education teachers and students in higher grades. Baltic Journal of Sport and Health Sciences, 4(95), 9-15.

Massie, J.E. (2002). The Relationship Between Childhood and Adolescent Physical Activity Experiences and Adult Physical Activity Levels (Dostoral Dissertation). Southern Illinois University, Carbondale.

Masten, A., Best, K., \& Garmezy, N. (1990). Resilience and development: Contributions from the study of children who overcome adversity. Development and Psychopathology, 425-440.

Paquette, K. R., \& Rieg, S. A. (2016). Stressors and coping strategies through the lens of Early Childhood/ Special Education pre-service teachers. Teaching and Teacher Education, 57, 51-58.

Penedo, F. J., \& Dahn, J. R. (2005). Exercise and wellbeing: A review of mental and physical health benefits associated with physical activity. Current Opinion in Psychiatry, 18(2), 189-193.

Ramirez, E. (2007). Resilience: A concept analysis. Nursing Forum, 42, 73-82.

Reeves, T. D., \& Lowenhaupt, R. J. (2016). Teachers as leaders: Pre-service teachers' aspirations and motivations. Teaching and Teacher Education, 57, 176187.

Reich, J. W., Zautra, A. J., \& Hall, J. S. (2010). Handbook of adult resilience. New York: The Guilford Press.

Salmon, P. (2001). Effects of physical exercise on anxiety, depression, and sensitivity to stress: A unifying theory. Clinical Psychology Review, 21(1), 33-61.

Saygın, Ö., \& Ayhan, Y. F. (2015). The investigation of physical activity experiences of instructors in childhood and adolescence and their physical activity levels in adulthood. International Refereed Academic Journal of Sports, Health And Medical Sciences, 15(5), 43-53.

Sharplin, E., O’Neill, M., \& Chapman, A. (2011). Coping strategies for adaptation to new teacher 
appointments: Intervention for retention. Teaching and Teacher Education, 27, 136-146.

Smith, B. W., Dalen, J., Wiggins, K., Tooley, E., Christopher, P., \& Jennifer Bernard, J. (2008). The Brief resilience scale: Assessing the ability to bounce back. International Journal of Behavioral Medicine, 15, 194200.

Spalding, T. W., Lyon, L. A., Steel, D. H., \& Hatfield, B. D. (2004). Aerobic exercise training and cardiovascular reactivity to psychological stress in sedentary young normotensive men and women Psychophysiology, 41, 552-562.

Southwick, S. M., Vythilingam, M., \& Charney, D. S. (2005). The psychobiology of depression and resilience to stress: Implications for prevention and treatment. Annual Review of Clinical Psychology, 1, 255-291.

The Ministry of Health Public Health Agency of Turkey. (2014). Turkey physical activity guide. Ankara: Kuban Matbaacılık ve Yayıncılık.
Walker, S., Sechrist, K., \& Pender, N. (1987). The health-promoting lifestyle profile: Development and psychometric characteristics. Nursing Research, 36(2), 76-81.

Wankel, L. M., \& Berger, B. G. (1990). The psychological and social benefits of sport and physical activity. Journal of Leisure Research, 22(2), 167-182.

Warburton, D. E., Nicol, C. W., \& Bredin, S. S. (2006). Health benefits of physical activity: The evidence. Canadian Medical Association Journal, 174(6), 801809.

Yazıc1, H., \& Altun, F. (2013). Conditions of beginning teaching and anxiety perceived in teacher candidates. 3rd World Conference on Learning, Teaching and Educational Leadership (pp. 974-977). Brussels: Academic World Education and Research Center .

Yıldırım, A., \& Şimşek, H. (2009). Sosyal Bilimlerde Nitel Araştırma Yöntemleri. Ankara: Seçkin Yayıncılık. 